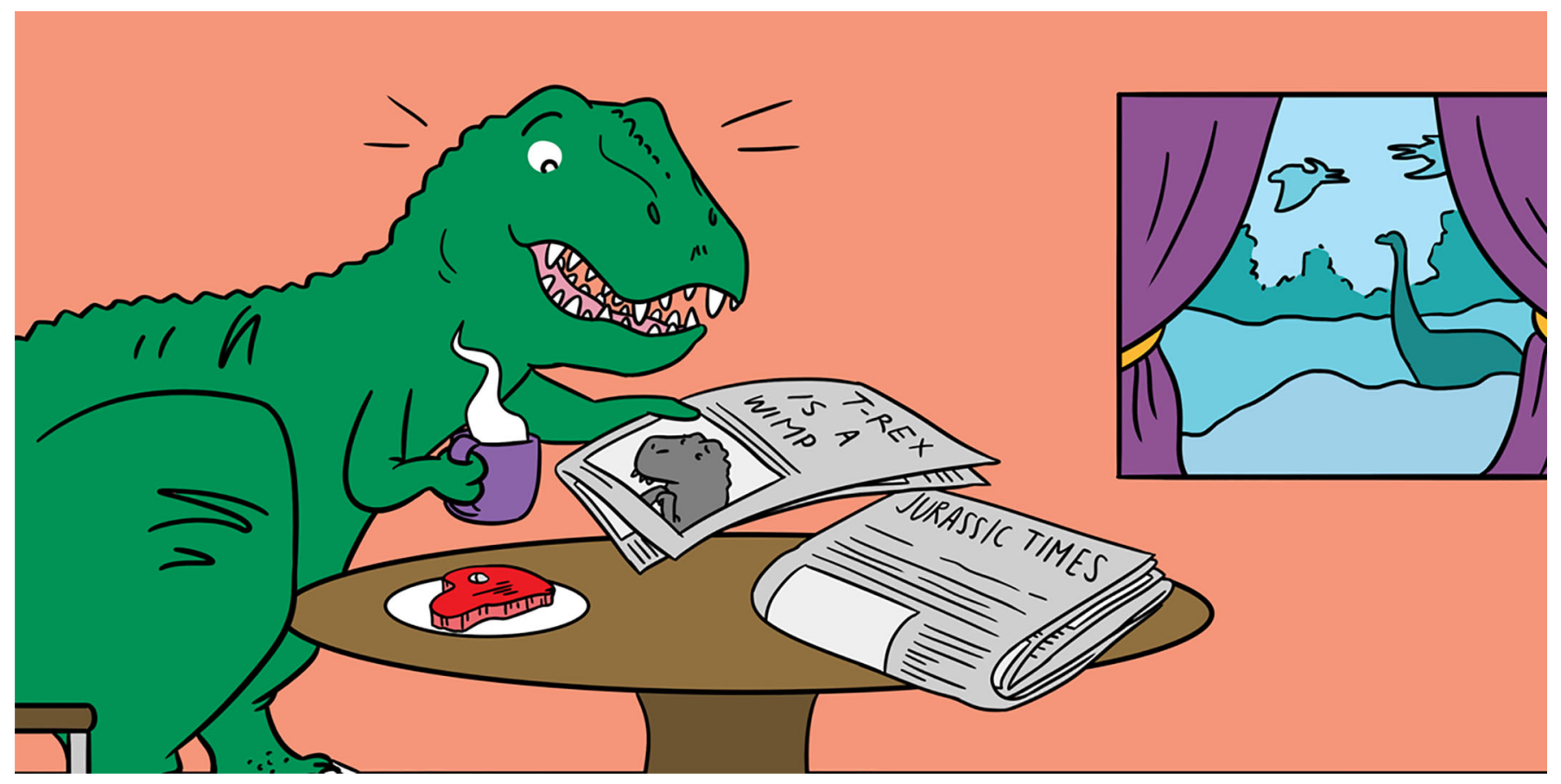

\title{
WAS TYRANNOSAURUS REX A FEROCIOUS PREDATOR OR A WIMP?
}

\section{Jack Thomas Rhodes Wilkin ${ }^{1 *}$ and David W. E. Hone ${ }^{2}$}

${ }^{1}$ Camborne School of Mines, University of Exeter, Exeter, United Kingdom

${ }^{2}$ School of Biological and Chemical Sciences, Queen Mary University of London, London, United Kingdom

\section{YOUNG REVIEWERS:}

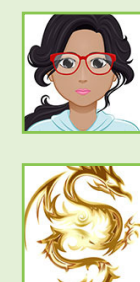

ASHIMA

AGE: 12

AVANI

AGE: 8

है 9 SANSKRITI

AGE: 13
Tyrannosaurus rex is the most famous dinosaur in the world: beloved by paleontologists and the public alike (especially kids). How $T$. rex lived is one of the most hotly debated topics in dinosaur research. $T$. rex was the largest predator in its ecosystem with a powerful and (possibly) poisonous bite. It has been suggested, however, that $T$. rex was a scavenger, like the dinosaurian equivalent of a vulture, rather than an active predator. The aim of this article is therefore to examine the behavior and lifestyles of these incredible animals and to provide you with clues on whether T. rex was a predator.

\section{INTRODUCTION}

Tyrannosaurus rex is the most famous and most beloved dinosaur on the planet. The genus Tyrannosaurus only contained a single species, T. rex. The name T. rex appropriately translates to Tyrant Lizard King. The first T. rex skeleton was unearthed by Barnum Brown in 1900 and was described and named by Henry Fairfield Osborn 5 years 


\section{Figure 1}

Drawing of a T. rex skull compared to that of a human.

\section{PREDATOR}

A meat-eating animal that kills its own prey

\section{CRETACEOUS}

The final period of the Mesozoic (which also included the Triassic and Jurassic) which lasted from 145 to 66 million years ago.

\section{TYRANNOSAURIDS}

A group of giant meat-eating dinosaurs that lived in North America and Asia during the latter part of the Cretaceous. Includes Tyrannosaurus and its closest relatives, such as Albertosaurus and the

Asian Tarbosaurus.

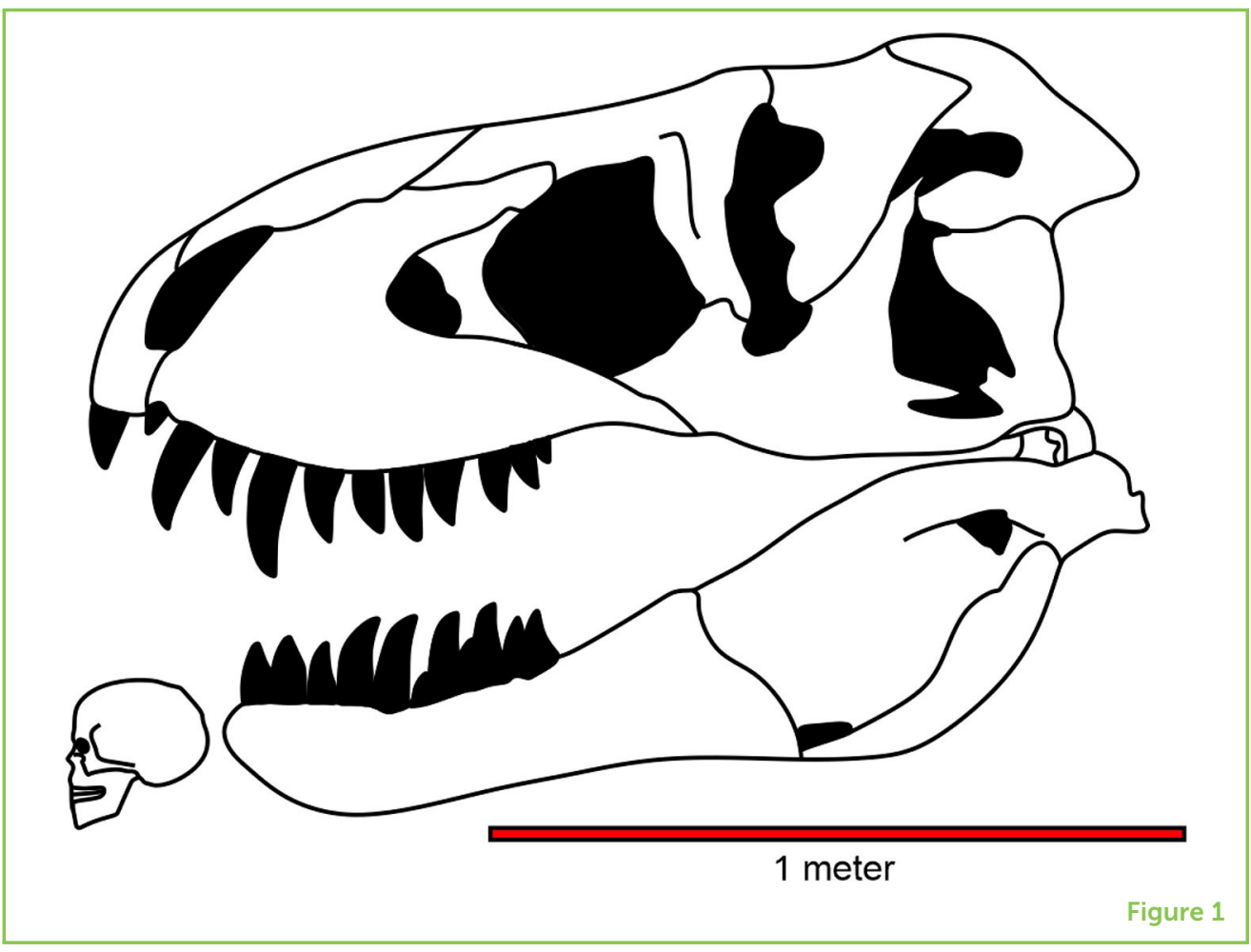

later [1]. T. rex was the largest predator in North America during the Late Cretaceous - the last period in which dinosaurs (not including birds) lived-between 68 and 66 million years ago. Much of what we know about T. rex comes from the mid-western United States. T. rex was a theropod (the group of predominantly meat-eating dinosaurs) that could reach up to $12 \mathrm{~m}$ (or 40 feet) in length and could have weighed as much as 8 metric tons, which is much more than an African Elephant bull!

\section{A GIANT SKULL WITH THE BITE EVER}

The most striking feature of Tyrannosaurus is their giant skulls which

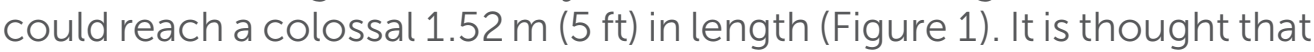
T. rex had the strongest bite force of any land animal that has ever lived. Computer simulations based on the shape and strength of T. rex's skull showed that its bite force was incredibly powerful. For you to have an idea of how powerful it was, T. rex's bite was up to 114 times stronger than that of most humans [2].

In contrast to the thin and blade-like teeth of most other theropods (which include Allosaurus, Velociraptor, and even birds), the teeth of tyrannosaurids were oval in cross-section. The thick cross-section of tyrannosaurid teeth shows that they were very strong, and this was confirmed by a $20-\mathrm{cm}$ coprolite (fossilized poo) from Canada, which was packed with bone fragments. The broad teeth of tyrannosaurids 


\section{SEPTIC BITE}

This is when a bite allows bacteria to move from the mouth to a wound which leads to a bacterial infection and eventually blood poisoning - a condition called sepsis. provided structural support to withstand the stresses associated with subduing struggling prey.

It has been hypothesized that tyrannosaurs had septic bites. The shape and angle of the spaces between tooth serrations of tyrannosaurids most closely resemble those of Komodo dragons, a species known for their septic bites. Grease and other food particles become trapped between the $T$. rex's teeth serrations leading to colonization by septic bacteria, meaning that a non-fatal bite by a tyrannosaur would have led to a serious bacterial infection [3]. However, the tooth serrations are like those found in other theropods, so it would be hard to argue that tyrannosaurs were exceptional in this regard. Besides, because tyrannosaur mostly hunted prey much smaller than themselves, a septic bite would not have made that much difference to their effectiveness as a predator.

\section{THE SENSES OF T. REX}

T. rex had an amazing sense of smell. We know this because the size of the parts of the brain responsible for smell (the olfactory bulbs) are bigger compared to other theropods suggesting that this was behaviorally important to tyrannosaurs [4]. T. rex could locate prey over great distances like a Cretaceous vulture.

Their eyes were large for a theropod of its size, and computerized tomography scans of its fossilized brain and skull-which creates thousands of sequential X-ray images along with the fossilized brain and skull-show that the optic nerve, which carries information from the eyes to the brain, is very well-developed. On top of this, the eyes of tyrannosaurs faced forward. This would have given T. rex good depth perception. It could, therefore, judge distances, an adaption common to modern hunters. The size and position of the eyes, as well as brain structure, has led scientists to think that T. rex had eyesight as good as modern-day birds of prey [4].

\section{THE TINY POWERFUL ARMS OF T. REX}

The arms of T. rex were relatively tiny, about the size of a human's, though with different proportions and only two fingers (Figure 2). There has been much debate about the possible functions of their forelimbs. Rather than being useless, T. rex arms were muscular some estimates able to pull $180 \mathrm{~kg}$ (400 lbs) as estimated by the size of their biceps-though this is at the higher end of the estimates. This suggests that their arms did serve a purpose, but the exact nature of that purpose is still debated by paleontologists [5]. They are smaller and with less sharp claws than ancestral tyrannosaurs, so whatever they were doing with their arms, they were doing it less than their forbears. 


\section{Figure 2}

Diagram of a T. rex arm showing the bones of the arm (left) and how it would have looked when the animal was alive (right).

\section{SCAVENGER}

A meat-eating animal that finds and eats animals that are already dead.

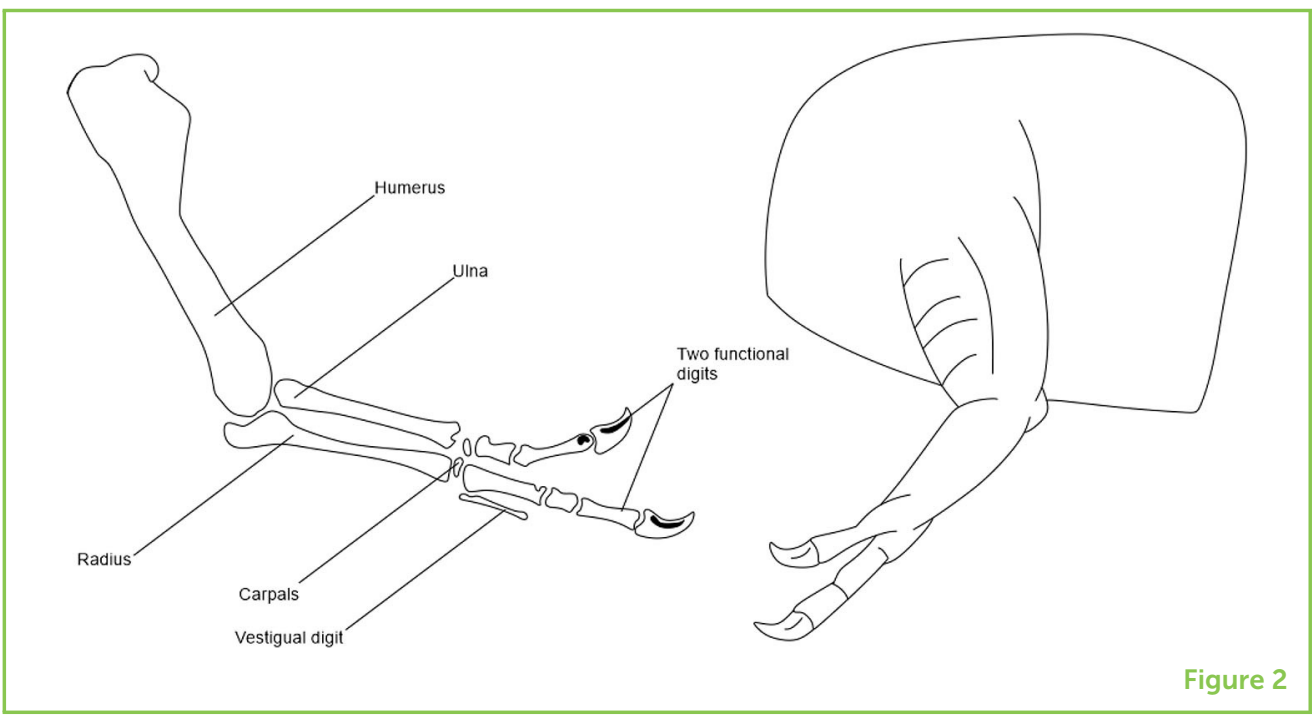

\section{GROWING UP}

Just like how human change as we get older so did dinosaurs. Unlike the large-headed and bulky adults, juvenile T. rex's were different with smaller, slender heads, long legs and thinner and more blade-like teeth. So, paleontologists concluded that young tyrannosaurs had a different lifestyle than adults. The longer limbs and more slender bodies meant that juveniles could run much faster than the adults, while the smaller skulls and bladed teeth imply that they did not crush bone like the adults.

\section{"WARRIOR" OR "WIMP"?}

The classic view of $T$. rex is that it was a terrifying predator and saying anything else seems almost heretical. In 1994, American paleontologist Jack Horner published an article that suggested that a view of T. rex for over a 100 years should be turned on its head ... T. rex, the Tyrant Lizard King, was a scavenger. The theory that $T$. rex and its close relatives were scavengers are based on tooth shape, sense of smell, and the size of the arms [6]. Many of these points have already been discussed in this paper, so what do you think? Was T. rex a scavenger or a predator?

The best answer is that, like most living carnivores T. rex both! There are good examples in the fossil record of large tyrannosaurs acting as scavengers [7], but there is definitive evidence of $T$. rex hunting, or at least trying to. Paleontologists have found several examples of failed attempts of predation where tyrannosaurs have left marks, or even teeth behind in their prey. One good example is seen is a duck-billed hadrosaur-a medium sized plant-eating dinosaurs called Edmontosaurus annectens, and very common during 
Figure 3

In the tail of this dinosaur,

Edmontosaurus annectens, there is clear evidence of predation of the tail. As you can see, one of the neural spines has been bitten of and the spine to the left of it has two puncture holes made by a tyrannosaur tooth pointed out by the yellow arrows. CC BY-SA 3.0.

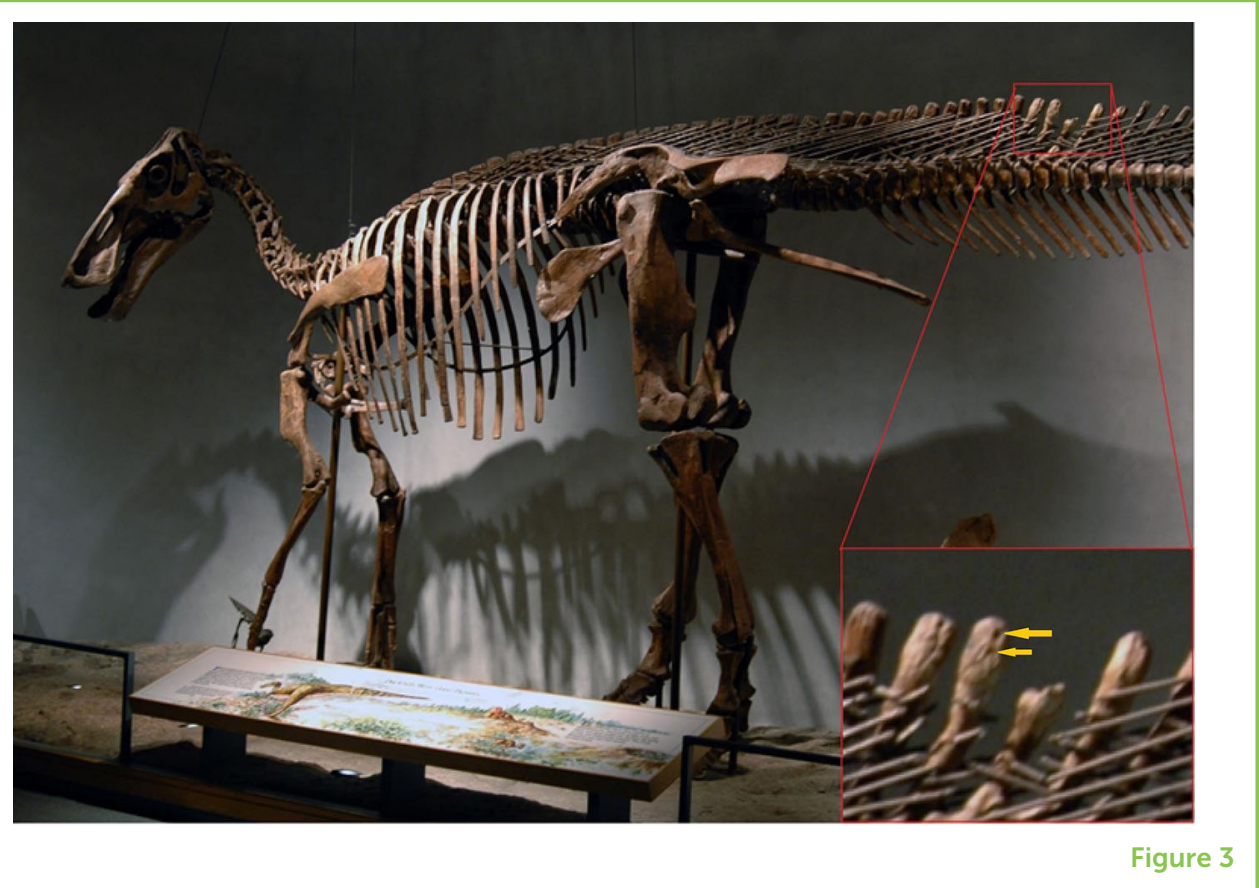

the Cretaceous-with a bite mark that removed parts of the tail (Figure 3). The bone regrowth around the tooth puncture marks shows that the animal survived T. rex's attack [8]. Other examples of failed predation include a hadrosaur vertebrae from the Hell Creek Formation of South Dakota that has a tyrannosaur tooth preserved inside the bone, which has healed and grown around it [9].

\section{CONCLUSION}

T. rex was the largest predator in North America during the last 2 million years of the age of dinosaurs. By analyzing the fossil remains of T. rex, paleontologists have discovered much about the behavior of these incredible animals. By studying the strength of their skulls, we know that they had the strongest bite force of any land animal that has ever lived. Although T. rex was an active predator, like most large predators, it also engaged in scavenging behaviors too when the opportunities arose.

\section{ACKNOWLEDGMENTS}

We would like to thank Pedro Morais (University of Algarve, Portugal) for his help in editing the article and all the suggestions which helped improve this work, as well as the Young Reviewers for all their hard work in reviewing this article. 


\section{REFERENCES}

1. Osborn, H. F. 1905. Tyrannosaurus and other Cretaceous carnivorous dinosaurs. Bull. AMNH 21:259-65.

2. Bates, K. T., and Falkingham, P. L. 2012. Estimating maximum bite performance in Tyrannosaurus rex using multi-body dynamics. Biol. Lett. 8:660-4. doi: $10.1098 / \mathrm{rsbl} .2012 .0056$

3. Abler, W. 1999. The teeth of the Tyrannosaurus. Sci. Am. 281:40-1.

4. Witmer, L. M., and Ridgely, R. C. 2009. New insights into the brain, braincase, and ear region of tyrannosaurs (Dinosauria, Theropoda), with implications for sensory organization and behavior. Anat. Rec. 292:1266-96. doi: 10.1002/ar.20983

5. Smith, M., and Carpenter, K. 1990. Forelimb biomechanics of Tyrannosaurus rex. J. Verteb. Paleontol. 10:43A.

6. Horner, J. 1994. Steak knives, beady eyes, and tiny little arms (a portrait of T. rex as a scavenger). Paleontol. Soc. Spec. Publ. 7:157-64. doi: 10.1017/S24752622 00009497

7. Hone, D. W. E., and Watabe, M. 2010. New information on scavenging and selective feeding behaviour of tyrannosaurids. Acta Palaeontol. Pol. 55:627-34. doi: 10.4202/app.2009.0133

8. Carpenter, K. 1998. Evidence of predatory behavior by carnivorous dinosaurs. Gaia 15:135-44.

9. DePalma, R. A., Burnham, D. A., Martin, L. D., Rothschild, B. M., and Larson, P. L. 2013. Physical evidence of predatory behavior in Tyrannosaurus rex. Proc. Natl. Acad. Sci. U.S.A. 110:12560-4. doi: 10.1073/pnas.1216534110

SUBMITTED: 18 October 2019; ACCEPTED: 06 July 2020;

PUBLISHED ONLINE: 14 August 2020.

EDITED BY: Pedro Morais, Center of Marine Sciences, Faculty of Sciences and Technology, University of Algarve, Portugal

CITATION: Wilkin JTR and Hone DWE (2020) Was Tyrannosaurus rex a Ferocious Predator or a Wimp? Front. Young Minds 8:101. doi: 10.3389/frym.2020.00101

CONFLICT OF INTEREST: The authors declare that the research was conducted in the absence of any commercial or financial relationships that could be construed as a potential conflict of interest.

COPYRIGHT @ 2020 Wilkin and Hone. This is an open-access article distributed under the terms of the Creative Commons Attribution License (CC BY). The use, distribution or reproduction in other forums is permitted, provided the original author(s) and the copyright owner(s) are credited and that the original publication in this journal is cited, in accordance with accepted academic practice. No use, distribution or reproduction is permitted which does not comply with these terms. 

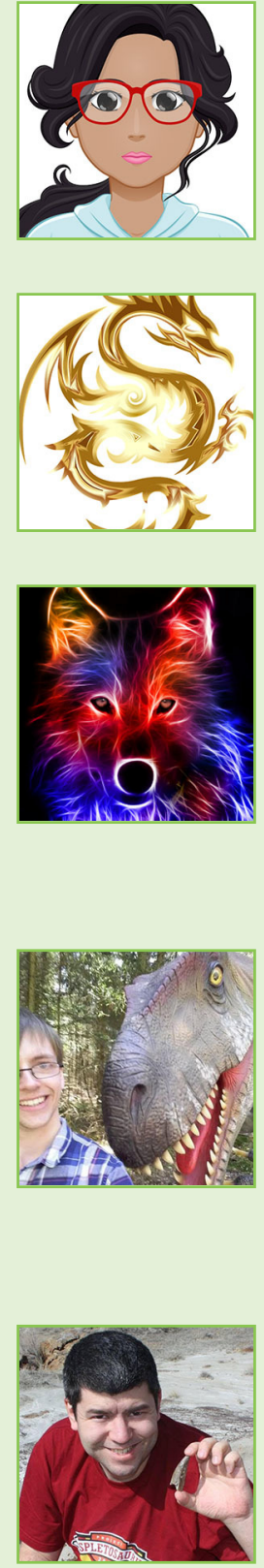

\section{YOUNG REVIEWERS}

\section{ASHIMA, AGE: 12}

$\mathrm{Hi}$, I am Ashima. I like to read fiction books and swim. I love to study. My favorite subject is mathematics. Quadratic functions are my favorite topic in mathematics.

\section{AVANI, AGE: 8}

Hello, I am Avani, I like to play a lot of games of every type. I also like playing with my puppy and video games. I like animals and nature a lot! So, in warm weather, I go outside and look at my beautiful surroundings, and nature around me! And in cold weather, I ski and play in the snow! Those are some things about me!

\section{SANSKRITI, AGE: 13}

Hello, my name is Sanskriti. I am 13 years old, and am going into eighth grade. My hobbies are crafting and reading. When I grow older I want to go into either biology or coding.

\section{AUTHORS}

\section{JACK THOMAS RHODES WILKIN}

I am a paleontologist and M.Sc. in geology student at the Camborne School of Mines, University of Exeter, in the United Kingdom. Before starting at CSM, I completed his B.Sc. (Hons.) in paleontology from the University of Portsmouth in 2017. I have helped look for fossils in the UK, Germany, France, and Poland. My research focuses on using the chemistry from fossils to help work out how the climate changed in the geological past. *jack.wilkinabtinternet.com

\section{DAVID W. E. HONE}

I am a paleontologist specializing in the behavior and ecology of dinosaurs and pterosaurs. I have helped find fossils in the UK, China, Canada, and Mexico and have named more than a dozen new species of ancient reptiles. Working out how extinct animals lived and behaved is really exciting as it involves trying to solve a complex problem with very limited information. I think this kind of work can be really inspiring to young people and a great demonstration of how science works to reveal new information. 